\title{
LA DEVOCIÓN DE LA CRUZ: ENTRE LA CRUELDAD HUMANA Y LA CLEMENCIA DIVINA
}

\author{
Manuel Delgado Morales \\ Bucknell University \\ [Anuario calderoniano (ISSN: 1888-8046), 2, 2009, pp. 97-109]
}

La presencia de la violencia en el teatro de Calderón ha sido observada ya por numerosos críticos e investigadores, entre otros por Ángel Valbuena Prat, Cesáreo Bandera, Thomas A. O'Connor, Debra D. Andrist y Michaela J. Heigl ${ }^{1}$.Violencia que se puede detectar, por otra parte, en muchas de las obras de nuestro dramaturgo, especialmente en obras filosóficas suyas como La vida es sueño y La hija del aire; históricas como Amar después de la muerte; bíblicas como Los cabellos de Absalón o El mayor monstruo del mundo; y, finalmente, en sus obras de honor, como El pintor de su deshonra, El alcalde de Zalamea, El médico de su honra y $A$ secreto agravio, secreta venganza.

$\mathrm{Ni}$ que decir tiene que las víctimas de la violencia en este último grupo suelen ser casi siempre mujeres, lo cual ha dado lugar a una se-

${ }^{1}$ Ver Valbuena Prat, 1963, p. 488; Bandera, 1975; O'Connor, 1988, pp. 89-94; Andrist, 1989; Heigl, 2002. 
rie de prejuicios y tópicos, no necesariamente motivados por los derechos de la mujer, que han sido oportunamente expuestos y criticados por Barbara Mujica:

La orientación realista de Menéndez Pelayo y de sus seguidores les llevó a considerar las obras de honor como expresión de las ideas populares y a asumir que Calderón, el autor más representativo de las tragedias de honor, defendió los asesinatos de las mujeres sospechosas de adulterio a manos de sus maridos. Como resultado de ello, Menéndez Pelayo condenó los dramas de honor en base a consideraciones de tipo moral ${ }^{2}$.

Desafortunadamente, y según ha observado la citada investigadora, la opinión de Menéndez Pelayo y la de quienes pensaban como él, entre otros Américo Castro, Menéndez Pidal y Alfonso García Valdecasas, ha obstaculizado durante décadas los estudios sobre el teatro español ${ }^{3}$. A mediados del siglo $\mathrm{xx}$, sin embargo, y según he explicado yo mismo en otro lugar, "un grupo de hispanistas de habla inglesa comenzó a rebatir» tales puntos de vista, "arguyendo, con razón, que Calderón no justifica la conducta de sus personajes, sino que trata, por el contrario, de despertar la conciencia moral de su público y hacerle cuestionarse el código del honor» ${ }^{4}$.

Aunque estoy de acuerdo con las razones expuestas por dichos hispanistas, los cuales suelen basar sus conclusiones en la lectura detallada del texto o en el close reading, me parece absolutamente necesario combinar este modo de lectura con el trasfondo filosófico-moral que pudo llevar a Calderón a mover los hilos de la violencia tal como se observa en la mayoría de estas obras. Con ello no solo habremos logrado trascender o superar la visión simplista o realista que presenta a nuestro dramaturgo como divulgador o simpatizante de las crueles prácticas populares, sino que habremos situado sus dramas de honor dentro del contexto filosófico-cultural que da sentido a gran parte de su obra. Me refiero especialmente a la filosofia estoico-cristiana, con la que, sin duda alguna, llegó a familiarizarse el joven Calderón durante sus años de estudio en el Colegio Imperial de los jesuitas y en las universidades de Alcalá y Salamanca.

\footnotetext{
2 Mujica, 1999, 339, traducción mía.

${ }^{3}$ Mujica, 1999, p. 339.

${ }^{4}$ Delgado, 2000, pp. 32-33.
} 
Dentro de la acerba colección de crímenes y episodios violentos que pueblan el teatro de Calderón, me ha parecido oportuno centrar mi atención en los numerosos que presenta La devoción de la cruz, una de las primeras obras salidas de su pluma, y cuyo caso de honra, venganza, incesto, agresiones, asaltos y muertes de todo tipo anuncian los múltiples y variados episodios que tendrán lugar en su producción posterior. Conviene advertir, sin embargo, que Calderón no usa la violencia por el rédito teatral o espectacular que hubiera podido sacar de la violencia en sí, lo cual vendría a dar la razón de alguna manera a Menéndez Pelayo y sus seguidores, sino que la presenta como consecuencia o resultado psicológico o moral de una serie de causas que él mismo establece y ordena con toda claridad y rigor. Entre dichas causas hay que destacar el orgullo, la ira, el apetito desordenado de venganza, la irracionalidad y, sobre todo, la crueldad de Curcio, lo cual da lugar a una serie interminable de muertes y crímenes que afectan gravemente a su esposa e hijos. De esta forma, se puede decir que más que una simple exposición de una serie de casos y hechos violentos, La devoción de la cruz contiene una dialéctica sostenida entre dicha violencia o, para ser más exactos, entre la crueldad que la define y la clemencia y la misericordia a las que aspira nuestro dramaturgo.

Lejos de ser exclusiva de Calderón, esta forma de contrastar la crueldad con la clemencia y la misericordia está en consonancia con la mentalidad de su época, ya que autores como Fray Luis de León, Cervantes, Guillén de Castro, Juan de Mariana y Pedro de Rivadeneyra aconsejan unánimemente al gobernante anteponer la última a la primera en la administración de justicia. Basándose en De Clementia de Séneca, Pedro de Rivadeneyra, por ejemplo, mantiene que el rey que no atiende a la misericordia puede caer en la crueldad: «Porque la misericordia que no está acompañada con la justicia es floja y reprensible, y la justicia sin misericordia no es justicia sino crueldad ${ }^{5}$.Y el mismo don Quijote le aconseja enfáticamente a Sancho en el momento en que este se apresta a gobernar la ínsula Barataria:

Cuando pudiere y debiere tener lugar la equidad, no cargues todo el rigor de la ley al delincuente, que no es mejor la fama del juez riguroso que la del compasivo... Al culpado que cayere debajo de tu jurisdicción

5 Tratado del príncipe cristiano, p. 546. 
considérale hombre miserable, sujeto a las condiciones de la depravada naturaleza nuestra, y en todo cuanto fuere de tu parte, sin hacer agravio a la contraria, muéstratele piadoso y clemente, porque, aunque los atributos de Dios todos son iguales, más resplandece y campea a nuestro ver el de la misericordia que el de la justicia ${ }^{6}$.

Un ejemplo adecuado de cómo contrapone Calderón la crueldad y la clemencia en La devoción de la cruz puede verse en la primera escena de la obra, en la que aparecen los graciosos Gil y Menga discurriendo sobre la mejor manera de sacar a la burra del hoyo en que se ha caído. Trayendo a colación lo que le pasó a un coche en Madrid, en circunstancias que Gil considera muy parecidas a las de la burra, este trata de convencer a Menga de que sería aconsejable poner frente al animal caído un harnero de cebada para lograr que se levante, en vez de recurrir a la crueldad de la fuerza o de los azotes:

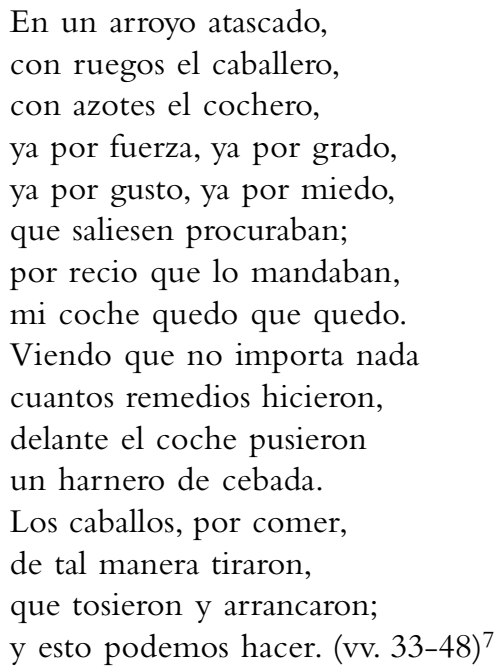

Otro ejemplo que ilustra cabalmente el pensamiento calderoniano sobre cómo se ha de actuar en situaciones violentas, en otras palabras, en casos de honra, duelo o guerra, puede verse al final de la obra, en

${ }^{6}$ Don Quijote de la Mancha, pp. 1416-1417.

${ }^{7}$ Cito de acuerdo con Calderón de la Barca, La devoción de la cruz, ed. M. Delgado, 2000. 
la escena en la que se presenta la lucha a muerte entre Curcio y Eusebio, y donde el padre le dice al hijo:

El acero de un noble, aunque ofendido, no se mancha en la sangre de un rendido, que quita grande parte de la gloria el que con sangre borra la victoria. (vv. 2192-2195)

Como he sugerido anteriormente, el trato concedido por Calderón a la crueldad y a la clemencia en La devoción de la cruz se entiende mejor si se lo considera a la luz de las ideas expuestas por Séneca en torno a la una y la otra en su De la ira, y De la clemencia, y, de manera especial, a la luz de la labor "cristianizante» que de estas ideas llevaron a cabo San Agustín, San Bernardo de Claraval y Santo Tomás de Aquino, labor que ha sido explicada con acierto por Daniel Baraz ${ }^{8}$. Curiosamente, la acción de La devoción de la cruz ocurre durante la Edad Media, época que, como ha indicado el citado Baraz ${ }^{9}$, en línea con Norbert Elias y Johan Huizinga ${ }^{10}$, suele asociarse generalmente con la crueldad. Según se desprende de una lectura atenta de la obra, el personaje que más se destaca por su violencia y crueldad es Curcio, el cual mata secretamente a su esposa Rosmira en lo más secreto de un monte porque sospecha, sin motivo, que esta le ha sido infiel mientras él se hallaba en Roma representando a la Señoría de Siena ante el papa Urbano III. Bien mirada, la acción de Curcio en contra de su esposa es un acto flagrante de venganza, la cual fue estudiada por Santo Tomás de Aquino al analizar la crueldad y la clemencia en su Suma teológica. Dado que resultaría prácticamente imposible resumir en pocas líneas el pensamiento de Santo Tomás en torno a dicha venganza, sirva la siguiente cita como punto de referencia para juzgar el posible alcance moral de la llevada a cabo por Curcio en La devoción de la cruz, así como de todas las efectuadas por los diferentes maridos calderonianos que consideran lesionado su honor:

La venganza se lleva a cabo mediante algún mal penal impuesto al pecador. Por consiguiente, en la venganza se debe tener en cuenta la in-

\footnotetext{
8 Baraz, 1998.

${ }^{9}$ Baraz, 1998, p. 195.

${ }^{10}$ Ver Elias, 1978, p. 194; Huizinga, 1996.
} 
tención del vengador. Pues si lo que principalmente intenta es el mal de aquel de quien se venga y en él se complace, eso es totalmente ilícito; porque gozarse del mal de otro es odio, opuesto a la caridad con que debemos amar a todos los hombres. Ni vale el que alguien se excuse diciendo que intenta causar un daño a quien injustamente se lo causó a él, como tampoco queda uno excusado por odiar a quien lo odia. Pues no hay razón que justifique el que peque yo contra otro porque este primero pecó contra mí, lo que sería dejarse vencer por el mal, cosa que prohíbe el Apóstol cuando dice (Romanos, 12, 21): No debes dejarte vencer por el mal, sino que debes vencer el mal con el bien ${ }^{11}$.

Aunque en la cuestión aludida de la Suma teológica, Santo Tomás mantiene abiertamente que «la venganza no es de suyo mala e ilícita», la llevada a cabo por Curcio, resulta claramente pecaminosa, en base, precisamente, a las reflexiones del propio Santo Tomás respecto a la ira que conduce a dicha venganza. Como ha explicado Luis Matías Ravioli en su análisis del pensamiento de Santo Tomás,

cuando el objeto de la ira sigue a la razón es algo elogiable y la llamamos «ira per zelum». Pero quien busca la venganza sin atender al modo (es decir, castigando a quien no lo merece o más de lo que merece), o no buscando la corrección del prójimo sino solo su mal, en este caso la venganza es pecaminosa y es llamada «ira per vitium» ${ }^{12}$.

Recurriendo, una vez más, a la terminología de Santo Tomás, podríamos decir que la venganza llevada a cabo por Curcio es claramente un caso de "ira per vitium», ya que este da muerte a su esposa sin que ella haya ofendido su honor: "tomé de mis pensamientos, / no de sus culpas, venganza» (vv. 705-706).Y a tenor de la advertencia de Séneca en De la ira, lo que debería haber hecho Curcio tendría que haber sido

rechazar... los primeros impulsos de la ira, sofocarla en su raíz y procurar no caer en su dominio. Porque si le presentamos el lado débil, es difícil librarse de ella por la retirada, porque es cierto que no queda ya razón cuando damos entrada a la pasión permitiéndole algún derecho por nues-

11 Suma teológica, II-IIae, cuestión 108.

12 Ravioli, 2008. 
tra propia voluntad. La pasión hará en seguida cuanto quiera, no limitándose a aquello que se le permita ${ }^{13}$.

Consejo sobre el que parece reflexionar el propio Curcio cuando reconoce la crueldad de su acción violenta:

El que intenta una traición antes mire lo que hace, porque una vez declarado, aunque procure enmendarse, por decir que tuvo causa, lo ha de llevar adelante. (vv. 1334-1339)

Ya he observado en mi edición de La devoción de la cruz $z^{14}$ el estado de ignorancia y de sinrazón en el que se sitúa Curcio con su forma de pensar y de actuar, estado que ha sido observado también por Bruce Wardropper, cuando, en base al Examen de ingenios de Huarte de San Juan, mantiene que la «facultad racional» de Curcio queda debilitada por la fuerza que ejerce en su imaginación la «facultad irascible» ${ }^{15}$.

Poco a poco, y a través de la exposición de la pasión de la ira que se adueña de Curcio, Calderón sitúa al espectador frente al fenómeno de la crueldad y de la violencia, no solo desde la perspectiva corporal o fisica inherente a dicha violencia, aspecto que se correspondería estrechamente con la visión senequista en torno a la crueldad, sino, principalmente, desde el punto de vista psicológico y espiritual, componente que, como ha explicado Daniel Baraz, establece una diferencia importante entre el pensamiento de Séneca y el de San Agustín, Santo Tomás y San Bernardo de Claraval ${ }^{16}$. En línea con el pensamiento de estos doctores de la Iglesia, Calderón dedica la mayor parte de su obra a mostrar el daño psicológico y espiritual que la crueldad de Curcio produce en su esposa e hijos. Daño que implica, por una parte, que la esposa inocente sea acusada y agredida injustamente y, por otra, que los hijos se maten entre ellos o mueran a manos de extraños, o

13 Séneca, De la ira, VIII.

14 Delgado, 2000, p. 35.

15 Wardropper, 1970.

16 Baraz, 1998, pp. 199-206. 
que se sientan abandonados y desterrados en el monte o en el convento. Ahora bien, el mayor exponente del daño causado por Curcio a Eusebio y Julia, es la atracción incestuosa del uno hacia el otro, así como la multitud de crímenes que ambos llevan a cabo como consecuencia de su sentimiento de desesperación y abandono. Tiene razón, en este sentido, Melveena McKendrick cuando afirma que Curcio no solo se muestra incapaz de percibir la realidad, sino que transmite dicha incapacidad a toda su familia ${ }^{17}$. Es más, arguyendo, con razón, que «la falsedad e insuficiencia de las percepciones del hombre se entretejen tupidamente... en la tela de la comedia, su acción y sus personajes» ${ }^{18}$, la citada hispanista observa la misma insuficiencia de percepción en el pintor, el astrólogo y el poeta que aparecen en la primera versión de la obra, la cual lleva por título La cruz en la sepultura.

Parafraseando a Santo Tomás, quien cita a su vez el De la clemencia de Séneca en su razonamiento, podríamos decir que al irritarse «sin haber sido ofendido y contra alguien que no es pecador» ${ }^{19}$, Curcio no solo se muestra "cruel, fiero o salvaje» contra su familia, sino que lleva a sus hijos y a la misma sociedad de Siena al estado de sevicia y fiereza descrito por el propio Santo Tomás. No en balde, una de las palabras que usa con más frecuencia Calderón para describir a Eusebio y sus emociones es el término "fiera», al mismo tiempo que los asesinatos, muertes y venganzas de este, como los de Julia y el pueblo de Siena, ocurren principalmente en un monte poblado de fieras.

Al igual que la crueldad y la violencia, el recurso a la clemencia y la misericordia divinas a través del símbolo de la cruz ha sido malinterpretado y ridiculizado por quienes, en opinión de Alexander Parker, no están dispuestos a mostrar ninguna simpatía por su contenido católico ${ }^{20}$. Ya en el siglo XVIII, por ejemplo, y como resultado de la mentalidad ilustrada, La devoción de la cruz fue denostada en Francia por razones de política y libertad religiosas. Uno de los detractores más implacables fue Sismonde de Sismondi, el cual llegó a afirmar que el objetivo de Calderón no era otro que el de "convencer a los espectadores cristianos de que la devoción a este signo de la Iglesia (la

17 McKendrick, 1989.

18 McKendrick, 1989, p. 319.

19 Suma teológica, II IIae.

20 Parker, 1949, pp. 404-405. 
cruz) bastaba para excusar todos los crímenes y asegurar la protección de la Divinidad ${ }^{21}$. George Ticknor, por su parte, consideró ofensiva La devoción de la cruz porque, según él, se devuelve la vida a un criminal como Eusebio con el fin de poder absolverlo de sus pecados y transportarlo directamente al cielo ${ }^{22}$. A Ticknor llegó a molestarle incluso que La devoción de la cruz tuviera admiradores incondicionales no sólo en la católica España, sino, como él afirma, dentro de la «cristiandad protestante».

Como es de suponer, la reacción a tales despropósitos no se hizo esperar. De entre las múltiples y firmes respuestas ante lo que llegó a considerarse como un ataque basado en la ignorancia, la exageración y la mala fe, me parece oportuno destacar la de Alexander Parker, el cual mantiene que la devoción de la cruz de Eusebio es «la señal externa de una disposición interna del alma», y que la misma cruz es «el símbolo de la paz entre los hombres, y entre la Humanidad y el Creador. Y cada vez que la cruz se menciona en el diálogo se asocia con la clemencia, y cada vez que aparece en la escena se asocia con un acto de clemencia» ${ }^{23}$. En otra palabras, y según los términos en que se expresa el gracioso Gil en la primera escena de la obra, la cruz ha de ser considerada como equivalente al harnero de cebada que puede ayudar a la burra a salir del lodazal, resultando, en consecuencia, un recurso más adecuado y eficaz que los azotes y la venganza. Como se puede ver, esta última opción es la única que entiende y elige el pueblo de Siena, el cual insiste en negarle la sepultura eclesiástica a Eusebio y dejar su cuerpo a merced de "las fieras y las aves» (v. 2435) después de haberle dado muerte. Ante esta crueldad, el mismo Curcio no puede por menos de exclamar:

¡Oh villana venganza!

¿Tanto poder en ti la ofensa alcanza

que pasas desta suerte

los últimos umbrales de la muerte? (vv. 2430-2434)

21 Sismondi, 1813, p. 131.

22 Ticknor, 1965, p. 433.

23 Parker, 1949, pp. 404-405. 
Teniendo en cuenta, una vez más, la opinión de quienes han atacado el perdón y la clemencia aplicados por Calderón a Eusebio, se puede decir que el estado de la cuestión no reside únicamente en si estos muestran antipatía o no hacia las creencias católicas del dramaturgo, sino también en si han llegado realmente a entender en todo su alcance la crueldad y la clemencia puestas sobre las tablas por Calderón. Frente a la importancia legal y política que Séneca atribuye a la crueldad o a la violencia corporales, autores como San Agustín y San Bernardo, basándose en la dicotomía cuerpo-alma, insisten especialmente en el lado espiritual de la crueldad, es decir en los efectos que dicha crueldad puede producir en el individuo o en la comunidad que la practican. En base a ello se puede decir que la esposa y los hijos de Curcio no son las únicas víctimas de la crueldad de este o de su concepto del honor, y por extensión, del pueblo de Siena, sino que también lo son, en sentido reflexivo, los propios agentes de dicha crueldad, es decir, Curcio y Siena.Y en la medida en que Eusebio y Julia llevan a cabo toda suerte de crímenes y venganzas continúan y perpetúan la cadena de violencia que había iniciado Curcio con su orgullo y su código del honor.

Observadas en su conjunto, es decir en el devenir completo de la acción dramática, la crueldad y la clemencia de La devoción de la cruz se avienen perfectamente con el esquema establecido por San Agustín en torno a la crueldad. De acuerdo con el obispo de Hipona, esta tiene su origen en el estado caído de la humanidad, la cual necesita, a su vez, de la gracia divina ${ }^{24}$. Mientras que, según este esquema, la crueldad es algo connatural al estado de la humanidad caída, la misericordia solo se consigue a través del parentesco que nos da el sufrimiento. Si, como mantiene San Agustín, la crueldad es el estado natural de los que no disfrutan de la gracia divina ${ }^{25}$, podemos concluir que Calderón tipifica la conducta de Curcio y de Siena como contrarias al cristianismo.

Al oponerse a la crueldad y a la violencia que la acompaña, y al ofrecer como contrapartida la misericordia divina, la cual se pone continuamente de manifiesto a través de los muchos casos en que la cruz interviene a favor de Eusebio, Calderón no hace más que reafirmar la

${ }^{24}$ Ver Baraz, p. 202.

${ }^{25}$ Ver Baraz, p. 202. 
contribución cristiana al derecho y a la administración de justicia, algo que, como es sabido, dista mucho del pensamiento de Séneca, el cual considera la misericordia como «el vicio del ánimo débil que sucumbe ante los males ajenos» ${ }^{26}$. De ahí que nuestro dramaturgo concluya su obra como la empezó el villano Gil: «¿No hay quien una cola tenga, / pudiendo tenerla mil?» (vv. 5-6), o dicho de otro modo, ¿no hay entre los presentes nadie que le eche una mano a la burra caída, en otras palabras, a su semejante? O, apurando más el argumento, si Dios y la cruz nos dan ejemplo de misericordia y clemencia infinitas ¿por qué el individuo y la sociedad recurren al uso de la violencia en casos en los que ni siquiera les asisten la verdad o los hechos?

A todo lo expuesto, habría que añadir, para concluir, la gran utilidad que puede representar La devoción de la cruz para quienes intenten adentrarse en los numerosos casos de honra, venganza y crueldad que pueblan el teatro de Calderón, ya que al ser obra religiosa, al mismo tiempo que de honor, nos ofrece una pista sumamente valiosa sobre el pensamiento de nuestro dramaturgo en torno a los casos de honor y violencia en los que no introduce consideraciones religiosas de manera tan evidente como en la obra que hemos analizado en este ensayo.

${ }^{26}$ De la clemencia, $\mathrm{V}$. 


\section{Bibliografía}

Andrist, D. D., Deceit plus Desire Equals Violence: A Girardian Study of the Spanish "comedia», New York, Peter Lang, 1989.

Aquino, S. T. de, Suma teológica, II-IIae.

<http://hjg.com.ar/sumat/c/c108.html>

Bandera, C., Mimesis conflictiva, ficción literaria y violencia en Cervantes y Calderón, Madrid, Gredos, 1975.

Baraz, D., «Seneca, Ethics, and the Body: The Treatment of Cruelty in Medieval Thought», Journal of the History of Ideas, 7, 1998, pp. 195-215.

Cervantes, M. de, El ingenioso hidalgo don Quijote de la Mancha, en Obras completas, ed. Á. Valbuena Prat, Madrid, Aguilar, 1952.

Delgado, M., «Introducción», en P. Calderón de la Barca, La devoción de la cruz, ed. M. Delgado, Madrid, Cátedra, 2000, pp. 11-108.

Elias, N., The Civilizing Process, New York, Urizen Books, 1978.

Heigl, M. J., "Erotic Paranoia and Wife Murder in Calderonian Drama", Hispanic Review, 70, 2002, pp. 333-353.

Huizinga, J., The Autumn of the Midle Ages, tr. R. J. Payton y U. Mammitzsch, Chicago, University of Chicago Press, 1996.

McKendrick, M., «Los juicios de Eusebio: El joven Calderón en busca de su propio estilo», en El mundo del teatro español en su Siglo de Oro: Ensayos dedicados a John E. Varey, ed. J. M. Ruano de la Haza, Ottawa, Dovehouse Editions, 1989, pp. 316-319.

MujicA, B. "Golden Age / Early Modern Theater: Comedia Studies at the End of the Century», Hispania, 82, 1999, pp. 397-407.

O'Connor, T. A., Myth and Mythology in the Theater of Pedro Calderón de la Barca, San Antonio, Trinity University Press, 1988.

Parker, A. A., «Santos y bandoleros en el teatro español del Siglo de Oro», Arbor, 43-44, 1949, pp. 396-416.

Ravioli, L. M., «Los vicios capitales en la Suma teológica de Santo Tomás de Aquino», Foro de Teología Moral.

$<$ http://www.foromoral.com.ar/pagpub.asp?page=124\#_ftn10>

Rivadeneyra, P. de, Tratado del príncipe cristiano, en Obras escogidas, Madrid, Biblioteca de Autores Españoles, 1868.

SÉneCA, L. A., De la ira, trad. F. Navarro y Calvo, Alicante, Biblioteca Virtual Miguel de Cervantes, 1999.

- De la clemencia, trad. F. Navarro y Calvo, Alicante, Biblioteca Virtual Miguel de Cervantes, 1999.

Sismondi, S. de, De la littérature du midi de l'Europe, Paris, Treuttel et Wurtz, 1813.

Ticknor, G., History of Spanish Literature, New York, Gordian Press, 1965, 6. ed., vol. 2. 
Valbuena Prat, Á., Historia de la literatura española, Barcelona, Editorial Gustavo Gili, 1963.

Wardropper, B.W., "La imaginación en el metateatro calderoniano», en Actas del Tercer Congreso Internacional de Hispanistas, ed. C. H. Magis, México, El Colegio de México, 1970, pp. 923-930. 
